\title{
Organisational Change: Communicating to Schein's Operator, Engineer and Executive Occupational Sub-Cultures
}

\begin{abstract}
There has been substantial academic interest surrounding innovation, change management, and the individual attributes that permit and promote learning, organisational change and innovative behaviour. This research uses a psychometric tool known as the Instinctive Drives System ${ }^{\circledR}$ to measure preferred working styles in 3,943 employees from a range of international companies. The employees were then classified into three groups (Engineers, Operators and Executives) following Schein's (1996) classification of occupational subcultures. This study reveals significant differences between the occupational subcultures, suggesting that executives are more inclined towards variety, flexibility and change rather than routine and structure. In contrast, operators and engineers demonstrated preferences for logic and certainty. These results have a range of implications, for researchers and practitioners. Researchers can extend the results of this study, and further explore the differences found between executives and managers from different subcultures. Practitioners may use the results to initiate change to integrate preferred working styles.
\end{abstract}

Keywords: Change Management; Learning Behaviour; Occupational Culture; Working Styles; Innovation

\section{Introduction}

There has been considerable academic and practitioner interest focused on innovation, particularly when seen as the 'engine of change' (Ahmed, 1998, p. 31), whether the innovations are new to the world or only new to the firm concerned. In addition to examining the individual attributes that promote innovation, previous research has explored the link between innovation and change management (Palmer, Dunford \& Akin, 2005). This paper verifies Schein's (1996) theory of internal occupational cultures, through the use of the Instinctive Drives System ${ }^{\circ}$, a psychometric system designed to identify and compare the preferred working styles of individuals in organisational environments. Furthermore, we illustrate how innovation, organisational change management and individual learning can be supported by effective communication with three distinct and different occupational sub-cultures: operators, engineers and executives. This study examines how innate predispositions differ between these occupational sub-cultures, and what significance these differences may have in regards to implementation of organisational change programs, in particular exploring the role of communication styles in change management. The findings suggest the practice of implementing a profiling tool such as the Instinctive Drives 
System ${ }^{\circledR}$ has potentially numerous benefits for managers, employees, and practitioners in organisational environments.

First, this paper will examine literature regarding occupational sub-cultures and change management in regards to learning behaviour. Then, the paper discusses the Instinctive Drives System ${ }^{\circledR}$, and provides an example of a profile to illustrate the way the profiling tool works. The method used in this study is then shown, which is followed by the results found. Finally, the discussion and conclusion sections of the paper demonstrate the contribution that these findings make to existing research, and the implications they have for further research.

\section{Occupational Sub-Cultures and Learning Behaviour}

Occupational sub-cultures refer to the differences that exist in the organisational culture between broad job types within organisations. The occupational sub-cultures existing within commercial organisations may appear relatively similar, particularly when compared to the differences in the occupational cultures existing among police officers and dockworkers (Trice, 1993). Outwardly, employees in modern organisations are seen to focus on rational, empirical measurement; work towards future oriented goals; and frequently spend most of their working time in office environments. However, misconceptions can occur if cultural assessments are made based on these apparent similarities. Using the presence of similar backgrounds and the occupation of common areas to define occupational communities has been criticised as '... especially misleading' (Van Maanen \& Barley, 1984, p. 295). Furthermore, Schein (1990, p. 111) asserted that the deepest levels of culture are cognitive: '... thought processes that the group comes to share will be the ultimate causal determinant of feelings, attitudes, espoused values, and overt behavior'.

Research into these cognitive factors of culture has established a number of different labels, such as mental models, thought worlds, or shared systems of meaning (Dougherty, 1992; Hayes \& Fitzgerald, 2007; von Meier, 1999). Research has also shown that different systems of cognition held by occupational groups within a single organisation can present barriers to innovation, knowledge sharing and the development of learning behaviour (Hayes, 2011). Further evidence presented by Hyland, Gieskes 
and Sloan (2001) suggests that an engineering occupational subculture plays a larger role than ethnic background in determining its member's view of learning behaviour.

Schein (1996) suggested that organisational learning and change failures were primarily due to inadequate understanding of occupational cultures existing within organisations. He theorised that three broad cultural groups exist within organisations: engineers (technocrats) who design and monitor the technology supporting an organisation's operations; operators who deliver products and services; and executives who primarily focus on financial performance. Comparisons of sub-cultural attributes are needed to obtain balanced insights into the process of developing learning behaviour within organisations. This research examines one theory of organisational sub-cultures; Schein's occupational culture groups of engineers, operators, and managers. We have followed Schein's (1996) suggestion to develop a greater understanding of these roles within workplaces, and an understanding that may lead to higher levels of performance, and lower levels of conflict.

Focussing on beliefs, values and assumptions, Schein (1995) contended that managerial culture was an inhibitor to organisational transformation and the development of learning behaviour. Specifically, a global culture of management (although Schein did acknowledge his use of a US perspective based upon familiarity as well as its dominant position in the production of management theories) inhibited the development of learning behaviour in organisations primarily by means of shared managerial assumptions. These assumptions included the widespread belief that managers had to be in control, decisive, certain and dominant at all times. In addition, a common belief was that "lone problem solvers" were regarded as heroic. Individual competition was considered to be the natural state, while teamwork was regarded as a practical necessity, instead of being seen as intrinsically desirable. A competition based work hierarchy provided security and status, and senior managers perpetuated this by acting in ever more decisive and controlling ways to express that status. One recent study by Pundzienė Alonderienè and Buožiūtė (2007) supports the idea that managers who communicate more competently with their employees, rather than focusing exclusively on their managerial status, are more capable of fostering learning behaviour. 
Managers were viewed as sharing an implicit mental model, indoctrinated in business schools, that '.. management deals with hard things - data, money, bottom lines, payoffs, production, competition, structure. And it is even better if these hard things can be quantified' (Schein, 1995, pp. 18 - 19). This mental model generally asserted that task issues should be given precedence over relationship issues, a privilege of management status is the freedom to stop learning, and short-term plans for short-term goals is the expected managerial orientation to time. Such a functionalist view of organisational culture reinforces the opinion of many researchers that culture is a variable that can be changed at will (Barley, 1983; O'Reilly \& Chatman, 1986; O’Reilly, Chatman and Caldwell, 1991; Schein, 1985, 1996; Lucas \& Kline, 2008). These previous studies have focused mainly on managers and professionals. However, whilst managers may try to impose values and standards of behaviour that specifically reflect the objectives of the organisation, there will also be an internal culture within the organisation at play, in the form of workgroups and created by individuals, each with their own behavioural quirks. Interactions between individuals and groups affect the whole system, and organisational culture should be studied from different viewpoints.

Martin (2002) proposes that there are at least three perspectives of organisational culture; the Integration - or normative - perspective, the Differentiation perspective with the view that in every organisation there are a collection of subcultures with commonalities and differences, and the Ambiguity perspective, addressing transient concerns that create short-lived alliances by acknowledging and accommodating the fragmentation and anxiety associated with a constant state of flux. This threeperspective view of cultural change is based on a premise that the culture of an organisation does not move from one perspective to another over time, but that all three perspectives may be relevant at any point in time. In other words, viewing organisational behaviour from a functional point of view lacks the detail required to get a complete understanding of an organisation's culture. Nevertheless, we believe Schein's operator/engineer/executive sub-cultures are worthy of further examination and their potential impact upon organisational change should be considered. 


\section{Change Management and Learning Behaviour}

Organisational Change (OC) is the systematic management of change in an organisation in the expectation of enhanced relationships, enhanced productivity and the successful development of learning behaviour, among the individuals within the organisation (Palmer et al., 2005). OC programs usually focus on the processes and tools that provide a structured path for groups and organisations to approach, execute and sustain change (Gilley, 2005). The techniques used to facilitate the development of learning behaviour include: readiness assessments; developing executive sponsors; creating awareness of the need for change; education and training to support desired change; helping employees move through the transition via coaching by managers; and methods to sustain the change through measurement systems and rewards.

However, despite their optimistic intentions, OC programs fail far more frequently than they succeed (Kotter, 2007; Lucey, 2008; Turner \& Crawford, 1998; Warrick, 2009). Although most OC failures aren't made public, OC success rates of between 20 and 50 per cent in Fortune 1,000 companies have been reported (Strebel, 1996). Recently, Warrick (2009) estimates OC success rates of around 30 per cent, noting that the failed 70 per cent includes OC efforts that damage organisations and their employees. This suggests that when such techniques fail, it is not simply a neutral event.

The impact of abortive OC extends well beyond the loss of anticipated benefits. Ramifications such as wasted time and money invested into the change program, employee stress and cynicism, reduced trust and confidence in leaders, and loss of momentum are associated with failed change programs (Lucey, 2008; Warrick, 2009). Furthermore, the effects of OC aren't limited by organisational boundaries; OC programs can positively or adversely affect families and communities. Clearly there is a critical need for innovative techniques to manage the implementation and continued use of OC programs. One approach that has been neglected to date is identifying, understanding and then accommodating the innate predispositions of individuals in an effort to maximise the success of OC programs.

Much of the extant change management literature focuses on ways to deal with employee resistance to management initiated OC (Strebel, 1996), and downplays the 
role of individual differences in regards to embracing change. Even after 50 years of study (Lewin, 1947; 1951) and repeated attempts by practitioners to increase the success rates of OC programs, there is little evidence of improvement (Warrick, 2009). The research reported in this article is novel, in that while studies of individual reactions have focussed on resistance (Stensaker \& Meyer, 2008) and negative reactions in response to OC programs (Bryant \& Cox, 2003), this study examines ways of understanding innate predispositions, and how these differ between occupational subcultures. By understanding individual and typical sub-cultural predispositions towards different types of communication channels and content, a better understanding of how to successfully implement OC programs across an organisation may be developed.

One recent study that demonstrates the value of effective communication in regards to successful organisational change is presented by Allen, Jimmieson, Bordia and Irmer (2007). These researchers suggest that when employees feel that there is a high level of quality communication within the workplace, such as direct conversations with managers, they are significantly more likely to respond positively to organisational changes. In light of these findings, methods of improving the quality of workplace conversations merit further research.

The importance of conversations in producing beliefs of autonomy, competence and organisational belonging in support of OC programs has been further demonstrated by previous research (DiVirgilio \& Ludema, 2009). Providing individuals with insights into their predispositions (and the predispositions typical of their subculture) and then using this knowledge to inform inter-personal dynamics and change conversations has the potential to improve employee engagement and support for change, and in turn impact OC outcomes. The Instinctive Drives (I.D.) System ${ }^{\circledR}$ is one way by which individual employees predispositions may be assessed, and appropriate communication strategies developed and implemented. Providing managers with the Instinctive Drives (I.D.) System ${ }^{\circledR}$ and coaching to develop the skills to improve communication with subcultures about OC programs, and leveraging knowledge of typical sub-cultural profiles, may assist to inoculate individuals to some of the stressors associated with change. 
Accordingly, Schein's (1996) conception of these three distinctive engineer, operator, and executive occupational cultures existing inside organisations does warrant further investigation. This study, along with further research, may be able to assess the validity of his view that managers act to impede innovation, and the validity of the previously demonstrated notion that an understanding of innate predispositions will help to reduce employee resistance to OC programs. This article examines a large database of psychological profiles and job descriptions to identify similarities and differences in preferred working styles for members of Schein's (1996) operator, engineer and executive occupational subcultures. This area of research has been previously investigated by Dainty, Cheng and Moore (2005), who provide an example of how an understanding of occupational roles and competencies can be achieved through the use of profiling tools, and how this understanding can then lead to higher performance. The following section of this article discusses the use of profiling tools to facilitate the understanding of strengths and vulnerabilities, which can then be applied to occupational subcultures in order to increase the success of OC programs through facilitating communication between organisational sub-cultures.

\section{The Instinctive Drives System ${ }^{\circledR}$ Profiling Tool}

The Instinctive Drives (I.D.) System ${ }^{\circledR}$ was developed in 1991 to help people identify their innate characteristics, and then work and live in congruence with these motivations (Burgess, 2007). Since then, the reliable and validated 40-item questionnaire (Fitzgerald, Ferres, Hamilton, \& Fitzgerald, 2005), and individual profile report that comprise the I.D. System ${ }^{\circledR}$ has been used by over 10,000 individuals. The majority of the people who are using the I.D. System ${ }^{\circledR}$ are working adults, and their four digit profile number, along with demographic data including age, gender, and job title have been recorded by Link-Up! International Pty Ltd, the company that develops, markets, and administers the I.D. System ${ }^{\circledR}$.

More specifically, the Instinctive Drives (I.D.) System ${ }^{\circledR}$ is designed to not only provide individuals with insight into their innate predispositions, but also provide insights into their personalised needs, talents, and vulnerabilities, as well as providing strategies for self-development (Burgess, 2007). These strategies allow individuals to understand and use the strengths associated with their particular profile to support effective 
communication within the workplace. Research indicates that implementing the I.D. System ${ }^{\circledR}$ improves understandings of self and team-mates, facilitates positive personal development, and increases team effectiveness (Fitzgerald et al., 2005, Fitzgerald, Dadich, Chapman, \& Fitzgerald, 2008).

Consistent with the tenets of positive psychology (Seligman \& Csikszentmihalyi, 2000), the I.D. System ${ }^{\circledR}$ aims to improve organisational management and leadership by focusing on individual strengths and effective intra-organisational communication (Fitzgerald, et al., 2005; Fitzgerald et al., 2008; Chapman, Hayes, \& Sloan, 2010). Furthermore, there is little intersection between the I.D. System ${ }^{\circledR}$ and other psychometric tools used in business settings, such as the Myers-Briggs Type Indicator (MBTI) and the Revised NEO Personality Inventory (NEO PI-R) (Fitzgerald, et al., 2005; Chapman, 2008a). The I.D. System ${ }^{\circledR}$ has demonstrated significantly high levels of test-retest reliability (Fitzgerald et al. 2005; Chapman, 2008b). More specifically, research comparing the test-retest reliability of the Myers-Briggs Type Indicator (MBTI) (Myers, McCaulley, Quenk, \& Hammer, 1999) and the I.D. System® (Burgess, 2007) found the I.D. System ${ }^{\circledR}$ had superior test-retest reliability (Chapman, 2008b).

According to the I.D. System ${ }^{\circledR}$ (Burgess, 2007), the innate drives of an individual can be expressed via scores on four distinct dimensions. The first of these is the Instinctive Drive to Verify® (Verify), which measures a person's need for detail as opposed to the need for concise answers. The second is the Instinctive Drive to Authenticate ${ }^{\circledR}$ (Authenticate), which measures the need for openness and honesty against the need for intuition and reading between the lines. The third is the Instinctive Drive to Complete ${ }^{\circledR}$ (Complete), which measures the need for harmony and routine against the need for flexibility and spontaneity. The fourth and final dimension is the Instinctive Drive to Improvise ${ }^{\circledR}$ (Improvise), which measures the need for a positive, dynamic environment against the need for logic and certainty.

Each person's I.D. System ${ }^{\circledR}$ profile is composed of four digits, measuring on a scale from one to nine the intensity of that individual's motivation to use or avoid using each of the four drives, and is represented visually in Figure 1. 


\section{Insert Figure 1 about here}

An individual with an I.D. ${ }^{\mathrm{TM}}$ profile of 4739 as shown in Figure 1, would be expected to readily accept information passed on by others (avoid verify) and would also accept this information as it was presented (use authenticate) without searching for any hidden meanings. In order to be more productive, they may benefit from variety and spontaneity (avoid complete) as they will readily move from one incomplete project to another. Their high improvise drive would mean that they were able to readily commit to projects without needing to fully understand their scope, and they would not be deterred by "impossible" challenges.

\section{Research aims and objectives}

This paper analyses the preferred working styles of 3,943 employees in order to investigate similarities and differences in operator, engineer and executive groups. It continues to consider the potential impact of innate predispositions displayed by each sub-culture upon OC efforts. Thus, this work not only provides an empirical test of Schein's (1996) theory, but allows for practical insights to be drawn in regards to the successful implementation of OC programs. In comparing the managerial, operator and engineer subcultures, it must be emphasised that all cultures have positive and negative aspects and, 'Ultimately cultures cannot be judged except in relation to some goal we are trying to accomplish' (Schein, 1995, p. 20). It is also noted that the comparisons made in this article are average measures of typical representatives of each of the 3 groups based upon their job description, and may not accurately represent the drives of any single individual within these groups.

\section{Method}

Link-up! Consulting Pty. Ltd., an organisation that has been collecting I.D System ${ }^{\circledR}$ profiles in the course of working with individuals and organisations over 6 years, provided a database containing I.D. System ${ }^{\circledR}$ profiles along with demographic information including job titles for 8,758 anonymous respondents, primarily from organisations in the United States (US) and Australia for analysis. These profiles are 
summarised by scores from 1 (strong propensity to avoid) to 9 (strong propensity to use) on each of the drives to verify, authenticate, complete or improvise when approaching work tasks. However, due to a non-standardised entry field for the job title demographic, only participants who had job titles which matched pre-determined criteria were included. From the large dataset, the job titles of 3,943 respondents who had completed the I.D. System ${ }^{\circledR}$ were able to be classified according to Schein's (1996) three groups of Executives, Engineers and Operators. For example job titles such as CEO, Vice President, and Senior Manager were classified as Executives. Job titles such as Consultant, Project Manager, and Sales Representative were classified as Operators. Job titles such as Engineer, IT Analyst, and Operations Manager were classified as Engineers. The means and medians of these respondent groups’ I.D. System ${ }^{\circledR}$ profiles were then analysed to determine if significant differences existed between the instinctive drives of the three groups.

\section{Results}

Classification of the 3,943 respondents resulted in there being 1,294 Executives, 2,236 Operators and 413 Engineers. This analysis included gender ratio and average age, as shown below in Table 1. The gender balance was approximately equal in the operator category, somewhat male dominated in the Engineer category, and clearly imbalanced in the executive category, with more than twice as many males compared to females. This gender imbalance in some categories has not affected the validity of the analysis as all analysed categories are sufficiently large to provide statistically significant findings.

\section{Insert Table 1 about here}

Furthermore, a report by Howard and Wellins (2009) shows that these gender ratios are consistent with occupational statistics for international companies, including Australian and US based firms. Additionally, while the average age was similar for both engineer and operator categories, executives had a significantly higher average age. This suggests that typical participants in the executive category are more likely to be male and older than participants in the engineer or operator categories. In relation to executive gender and age, the organisations represented in the data base are representative of the $21^{\text {st }}$ century populations of employed individuals from which they are drawn. 
After analysing the demographics of the participants, the differences between the groups in regards to their I.D. System ${ }^{\circledR}$ profile scores were considered. Figure 1 depicts the relationship between the groups across all four dimensions. Additionally, a pair-wise comparison of means for each of the four I.D. System ${ }^{\circledR}$ dimensions was conducted.

As shown in Figure 2, the scores in the executive group are noticeably different to both the engineer and operator groups across all four of the drives. These differences (as shown later in Table 2$)$ were found to be highly significant $(\mathrm{p}=0.01)$, a notable result as the standard deviations of measurements for all groups were similar (within drive variation less than $\left.+_{-} .05\right)$.

\section{Insert Figure 2 about here}

Particularly noticeable are the differences found on the Complete and Improvise drives, drives strongly associated with an innovative, changing organisation. Figure 2 demonstrates that executives displayed the opposite trend to the other two groups when examining the relationship between the Complete drive and the Improvise drive. Operators and engineers both had a higher drive to Complete in comparison to their drive to Improvise, but executives had a much lower drive to Complete, and a much higher drive to Improvise. In addition, the Improvise drive was the only drive in which there was an opposite drive identified amongst the subcultures. This is demonstrated by the average Improvise drive of executives being above the mid-point of five, with the other two sub-culture groups being well below five. This finding suggests that executives are driven to use the Improvise drive, as opposed to engineers and operators that are driven to avoid the Improvise drive.

Table 2 confirms the significance of the differences suggested by Figure 1 . There was a minor difference noted on the Verify drive between operators and engineers, but no other significant difference between these two groups was found. Pair wise comparisons of all drives between the executives and operators, and between the executives and engineers were found to have highly significant differences. 


\section{Insert Table 2 about here}

\section{Discussion}

Clear evidence of Schein's (1996) executive, operator, and engineer groups appeared from analysis of the sample of 3,943 individuals. The typical ID® System profiles of each sub-culture provide an understanding of the proclivities of people employed in these positions. In particular, executives are more likely to be driven towards flexibility, variety, and innovative environments. In contrast, Engineers and Operators are driven towards environments with logic and certainty, and more structured and routine based tasks.

These finding may provide opportunity for reflection by employees at all levels. By knowing the characteristics that appear to be prevalent in upper management positions, employees can modify their work behaviour to best fit the role which they aspire to in the organisation. An example of how this type of adaptation may be used is shown in the strategies provided to all individuals who complete the I.D. System ${ }^{\circledR}$ along with their profile. A manager who observes that most of the team display a high verify drive may ensure that future tasks are explained in more detail. Conversely, if most of the team displayed an avoid verify drive, the manager could ensure to present the key elements only. This finding complements the suggestions made by researchers such as Allen et al. (2007) and DiVirgilio and Ludema (2009), who propose that an increase in effective communication and conversation within the workplace leads to a more productive workforce.

More specifically, Allen et al. (2007) suggest that if managers are able to have more of an ability to effectively implement organisational change programs if they have a better understanding of how to talk to their employees. This findings of this research suggest that the use of language such as that provided by the I.D. System ${ }^{\circledR}$ gives managers this understanding, and enables them to have more effective workplace conversations with their employees.

Conversely, from the employee's perspective, an understanding of specific management characteristics may also increase the acceptance of the uncertainty generated by 
management through OC programs. This could also lead to more successful adoption of OC programs, and development of beneficial learning behaviour. For example, adoption of the I.D. System ${ }^{\circledR}$ (which itself can be considered an OC program) may be more successful when managers are able to use the increased understanding of innate predispositions to effectively manage resistance to change. Greater management understanding of the desires for certainty before changing routine work methods in the operator and engineer subcultures could lead to more structured change proposals with a greater likelihood of employee acceptance. This finding is particularly relevant in light of the low success rates of OC programs reported by Warrick (2009), as managers may be able to use this information to enable a more effective implementation of OC programs.

From a positive psychology perspective (Seligman \& Csikszentmihalyi, 2000) the current study provides a useful way for managers to focus on communicating to the strengths of employees, rather than focusing on aspects that need to be improved. The findings suggest that the use of a tool such as the I.D. System ${ }^{\circledR}$ allows more effective communication between various sub-cultures with organisations. This is achieved through providing an understanding of the strengths possessed by people with different innate predispositions.

The study makes a contribution to existing literature by addressing the need for further research into the sub-cultural roles of employees in organisational environments (Schein, 1996). Specifically, it was found that members of the Engineer, Operator, and Executive subcultures are able to consider and accommodate the innate drives likely to be present in members of other groups when they meet and work together. This provides an example of beneficial learning behaviour made possible through the use of a profiling tool such as the I.D. System ${ }^{\circledR}$ to improve intra-organisational communication. This finding also complements the research presented by Dainty et al. (2005), and builds further support for the potential benefits associated with the use of profiling tools within organisational environments. 


\section{Conclusion}

The significant differences found between the executive, operator and engineer groups provide further support for Schein's (1996) classifications. The results have application to those seeking to lead and manage change as they aid understanding of the drives that are likely to characterise operator, executive and engineer individuals. Consistent with positive psychology, the I.D. System ${ }^{\circledR}$ may improve the management of change and innovation efforts by supporting individual strengths and tailoring communication to match natural proclivities. Whilst the study found clear evidence of executive, operator and engineer sub-cultures, nexus views of organisational culture (Martin, 2002) have also been presented to extend Schein's conception of occupational culture.

\section{Implications for Organisations}

A range of implications arise from this study for managers and employees in organisations, particularly those involved with OC programs. Additionally, there are implications for practitioners developing strategies to improve workplace performance in organisations.

Employees working in companies that are considering the use of a profiling tool such as the I.D. System ${ }^{\circledR}$ may benefit from the findings of the current study. This may be experienced through more effective communication with co-workers and managers, more efficient transactions in terms of task-related discussions, and increased productivity as a result of being aware of the innate characteristics of colleagues. Managers, whilst also receiving these potential benefits, may be able to implement OC programs with more confidence, particularly if OC communication is tailored to match operator and engineer preferences for detail and certainty, and executive needs for the general vision of where the organisation is heading.

OC practitioners may build upon the findings presented here by examining new ways to develop an innovative climate in the workplace and reduce resistance to OC efforts. Understanding the characteristics of occupational subcultures present in organisations may provide opportunities to improve organisational process and innovation outcomes. 


\section{Implications for Future Research}

In addition to the above implications for organisations, this study has several implications for researchers extending current knowledge of the interaction between individuals preferred working styles and occupational culture. The findings of the study specifically address the need for further research into the differences between subcultures within organisational environments; however, there is still a need to further explore these differences, and establish more useful ways for managers and employees to communicate in light of existing occupational sub-cultures.

In addition, there are opportunities for researchers to take a number of directions when extending the current study in order to increase knowledge to this field of research. Firstly, research into OC can build upon the different levels of openness to innovative learning behaviour observed between different occupational sub-cultures. Secondly, future studies can focus on further empirical validation of tools such as the I.D. System ${ }^{\circledR}$. Thirdly, research into OC and organisational culture can examine the effect that the utilisation of profiling tools - and their subsequent impact on innovative learning behaviour - has on the culture within organisations.

\section{References}

Allen, J., Jimmieson, N. L., Bordia, P., \& Irmer, B. E. (2007). Uncertainty during organizational change: Managing Perceptions through communication. Journal of Change Management, 7, 187-210.

Ahmed, P. K. (1998). Culture and climate for innovation. European Journal of Innovation Management, 1(1), 30-43.

Barley, S. R. (1983). Semiotics and the Study of Occupational and Organizational Cultures. Administrative Science Quarterly, 28(3), 393.

Bryant, M., \& Cox, J. W. (2003). The Telling of Violence: Organizational Change and Atrocity Tales. Journal of Organizational Change Management, 16(5), pp.567 - 583.

Burgess, P. (2007) Natural born success: Discover the Instinctive Drives ${ }^{\mathrm{TM}}$ that make you tick!, Milton, QLD, Wrightbooks.

Chapman, G. R. (2008a). A canonical correlation analysis of the Myers-Briggs Type Indicator and the Instinctive Drives ${ }^{\mathrm{TM}}$ System. Paper presented at the Australian and New Zealand Academy of Management Conference.

Chapman, G. R. (2008b). The Reliability of Profiling Within the Workplace -A Comparison of Two Personality Measures. Paper presented at the 2008 Australian and New Zealand Academy of Management Conference, Auckland: New Zealand

Chapman, G. R., Hayes, K. J. \& Sloan, T. (2010). Innovation and Occupational Cultures - The Role of Identifying Working Styles. Paper presented at the 11th International CINet Conference: Practicing Innovation in times of discontinuity, Zurich, Switzerland, 5-7 September p. 232-239.

Dainty, A. R. J., Cheng, M., \& Moore, D. R. (2005). Competency-based model for predicting construction project managers' performance. Journal of Management in Engineering, 21(1), 2-9.

DiVirgilio, M. E., \& Ludema, J. D. (2009). Let's Talk: Creating Energy for Action through Strategic Conversations. Journal of Change Management, 9(1), pp. 67 - 85. 
Dougherty, D. (1992). Interpretive Barriers to Successful Product Innovation in Large Firms. Organization Science, 3(2), pp. 179 - 202.

Epton, S. R., Payne, R. L., \& Pearson, A. W. (1983). Managing Interdisciplinary Research: Second International Conference on the Management of Interdisciplinary Research. Chichester, UK.

Fitzgerald, J. A., Dadich, A., Chapman, G. \& Fitzgerald, J. (2008) Can the Instinctive Drives SystemM facilitate the management of occupational stress? Sydney, NSW, CInIS (Centre for Industry and Innovation Studies), College of Business, University of Western Sydney.

Fitzgerald, J. A., Ferres, N., Hamilton, K., \& Fitzgerald, J. (2005). What is Instinctive Drive ${ }^{\text {тм. }}$ A report on the validation process of the $I D^{\mathrm{TM}}$ system used to improve team performance Paper presented at the Australian Business and Behavioural Sciences Association Annual Conference

Gilley, A. (2005). The manager as change leader. Westport, CT: Praeger.

Hayes, K. J. (2011). Triple Helix Organisations, Communities of Practice and Time. In O. Rivera Hernáez \& E. Bueno Campos (Eds.), Handbook of Research on Communities of Practice for Organizational Management and Networking: Methodologies for Competitive Advantage (pp. 245-264). Hershey, USA: IGI Global

Hayes, K., \& Fitzgerald, A. (2007). Business and Research Forms of Debate: Argumentation and Dissent as Barriers to the Commercialisation of Innovations in Hybrid Industry-Research Organisations. International Journal of Technology, Policy and Management, 7(3), pp. 280 - 291.

Howard, A., \& Wellins, R. S. (2009). Holding women back: Troubling discoveries - and best practices for helping female leaders succeed. Pittsburgh, Pennsylvania: Development Dimensions International.

Hyland, P. W., Gieskes, J. F. B., \& Sloan, T. R. (2001). Occupational Clusters as Determinants of Organisational Learning in the Product Innovation Process. Journal of Workplace learning, 13(5), pp. 198 - 208.

Kassicieh, S. K., \& Radosevich, H. R. (1993, March 1993). From Lab to Market: Commercialization of Public Sector Technology. Paper presented at the Technology Commercialization Conference, Santa Fe, New Mexico.

Kotter, J. (2007). Leading Change: Why Transformation Efforts Fail. Harvard Business Review, 85(1), pp. $96-103$.

Lewin, K. (1947). Frontiers in Group Dynamics: Concept, Method and Reality in Social Science; Social Equilibria and Social Change. Human Relations, 1, pp. 5 -41.

Lewin, K. (1951). Field Theory in Social Science. New York: Harper and Row.

Lucas, C., \& Kline, T. (2008). Understanding the influence of organizational culture and group dynamics on organizational change and learning. The Learning Organization, 15(3), 277-287.

Lucey, J. J. (2008). Why is the Failure Rate for Organisation Change so High? Management Services, 52(4), pp. 10 - 19

Martin, J. (2002) Organizational Culture: Mapping the Terrain, Thousand Oaks, CA, Sage Publications, Inc

O'Reilly, C., \& Chatman, J. (1986). Organizational Commitment and Psychological Attachment: The Effects of Compliance, Identification, and Internalization on Prosocial Behavior. Journal of Applied Psychology, 71(3), 492.

O'Reilly, C. A., Chatman, J., \& Caldwell, D. F. (1991). People and Organizational Culture: A Profile Comparison Approach to Assessing Person-Organization Fit. Academy of Management Journal, 34(3), 487.

Palmer, I., Dunford, R., \& Akin, G. (2005). Managing organizational change: A multiple perspectives approach. New York: McGraw-Hill

Pundzienè, A., Alonderienè, R., \& Buožiūtè, S. (2007). Managers' Change Communication Competence Links with the Success of the Organisational Change. Engineering Economics, 54(4), 61-69.

Quirk, T. (2005). Science in the Service of the Nation State. Policy, 21(3), pp. 32 - 38.

Schein, E. H. (1985). Organizational culture and leadership. San Francisco: Jossey Bass.

Schein, E. H. (1990). Organizational Culture. American Psychologist, 45(2), pp. 109-119.

Schein, E. H. (1995). Organizational and Managerial Culture as a Facilitator or Inhibitor of Organizational Transformation, MIT Sloan School of Management Working Paper 3831, Cambridge, MA, USA.

Schein, E. H. (1996). Culture: the Missing Concept in Organization Studies. Administrative Science Quarterly, 41(2), pp. 229 - 241. 
Seligman, M. E. P., \& Csikszentmihalyi, M. (2000). Positive psychology: An introduction. American Psychologist, 55, 5-14.

Steiner, C. (2000). Teaching Scientists to Be Incompetent: Educating for Industry Work. Bulletin of Science, Technology and Society, 20(2), pp. $123-132$.

Stensaker, I., \& Meyer, C. B. (2008 xx nb incomplete ref). Change Capabilities or Cynicism? How Change Experience Influences Employee Reactions. Academy of Management Proceedings.

Strebel, P. (1996). Why do Employees Resist Change? Harvard Business Review, pp. 86 - 92.

Trice, H. M. (1993). Occupational Subcultures in the Workplace. Ithaca, NY: ILR Press, Cornell University.

Turner, D., \& Crawford, M. (1998). Change Power: Capabilities that Drive Corporate Renewal. Warriewood, Sydney: Business and Professional Publishing.

Turpin, T., Garrett-Jones, S., \& Rankin, N. (1996). Bricoleurs and Boundary Riders: Managing Basic Research and Innovation Networks. $R \&$ D Management, 26(3), pp. 267 - 282.

Van Maanen, J., \& Barley, S. R. (1984). Occupational Communities: Culture and Control in Organizations. Research in Organizational Behavior, 6, pp. 287 - 365.

von Meier, A. (1999). Occupational Cultures as a Challenge to Technological Innovation. IEEE Transactions on Engineering Management, 46(1), pp. 101 - 114.

Warrick, D. D. (2009). Developing Organization Change Champions. OD Practitioner, 41(1), pp. 14 - 19. 


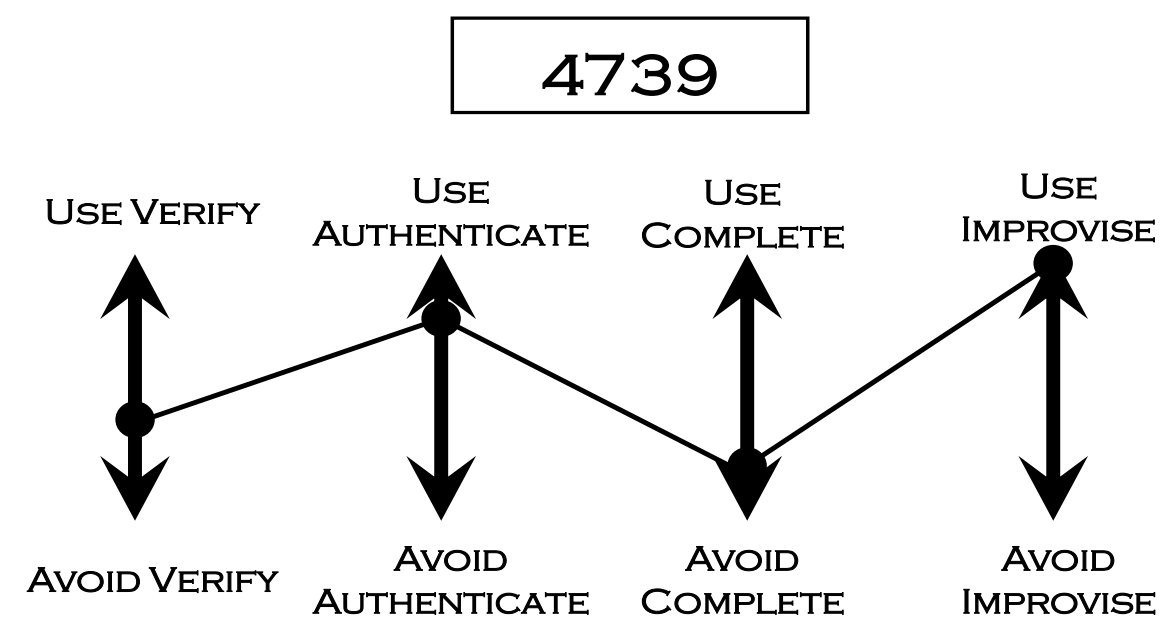

USE IMPROVISE AND AUTHENTICATE \& AVOID COMPLETE

Figure 1: Example of an I.D System ${ }^{\circledR}$ Profile

Table 1: Breakdown of Participants by Cultural Group, Gender, and Age

\begin{tabular}{|c|c|c|c|c|}
\hline $\begin{array}{c}\text { Schein's } \\
\text { Cultural } \\
\text { Group }\end{array}$ & $\mathrm{n}$ & Male & Female & $\begin{array}{c}\text { Average } \\
\text { Age }\end{array}$ \\
\hline Engineer & 413 & 257 & 156 & 36.66 \\
\hline Operator & 2236 & 1058 & 1071 & 37.35 \\
\hline Executive & 1294 & 882 & 399 & 43.50 \\
\hline
\end{tabular}




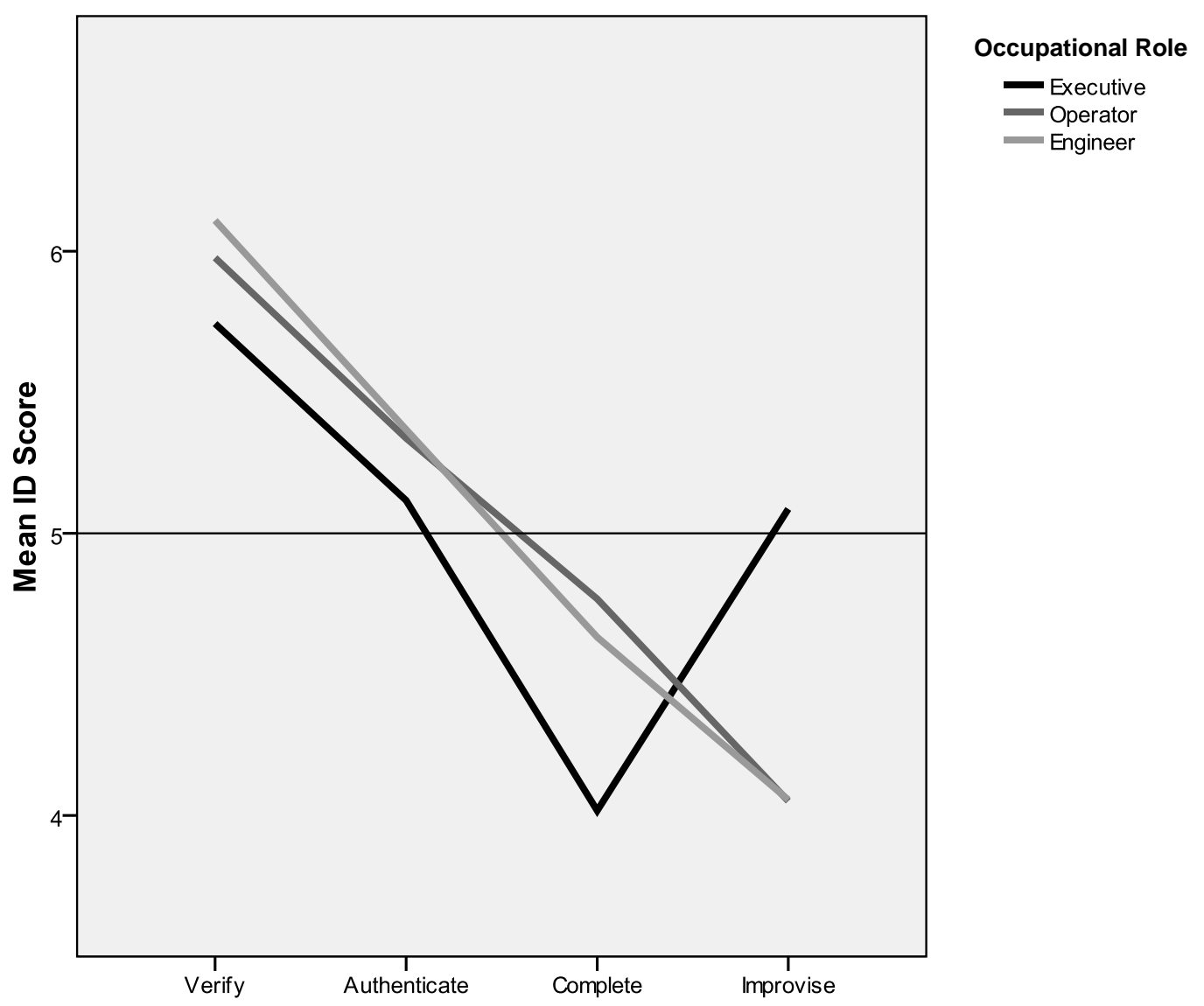

Figure 2: Differences in I.D System ${ }^{\circledR}$ Drives for Executive, Engineer and Operator Groups

Table 2: Significance of Differences in I.D System ${ }^{\circledR}$ Drives for Executive, Engineer and Operator Groups

\begin{tabular}{|c|c|c|c|}
\hline I.D. System® Drive & $\begin{array}{c}\text { Executive vs. } \\
\text { Engineer }\end{array}$ & $\begin{array}{c}\text { Executive vs. } \\
\text { Operator }\end{array}$ & $\begin{array}{c}\text { Engineer vs. } \\
\text { Operator }\end{array}$ \\
\hline Verify & $* * *$ & $* * *$ & $*$ \\
\hline Authenticate & $* * *$ & $* * *$ & $\mathrm{X}$ \\
\hline Complete & $* * *$ & $* * *$ & $\mathrm{X}$ \\
\hline Improvise & $* * *$ & $* * *$ & \\
\hline
\end{tabular}

* = significant differences at the $90 \%$ level

$* * *=$ significant differences at the $99.9 \%$ level

$\mathrm{X}=$ no significant differences found 